\title{
O QUE ESTAMOS ESTUDANDO SOBRE GÊNERO NA EDUCAÇÃO INFANTIL: AS LACUNAS NA FORMAÇÃO DOCENTE
}

\author{
QUÉ HEMOS ESTUDIADO SOBRE GÉNERO EN LA ENSEÑANZA INFANTIL: LOS \\ HUECOS EN LA FORMACIÓN DOCENTE
}

\author{
WHAT WE ARE STUDYING ABOUT GENDER IN EARLY CHILDHOOD \\ EDUCATION: THE GAPS IN TEACHER EDUCATION
}

\author{
Ariane CROCIARI ${ }^{1}$ \\ Marcia Cristina Argenti PEREZ ${ }^{2}$
}

RESUMO: O presente artigo tem como objetivo a investigação sobre o estudo do gênero na educação infantil e a formação docente nesta temática. Os dados da pesquisa foram obtidos a partir de uma abordagem bibliográfica. Fazendo uso da Base de Dados Scielo, utilizando os temas principais: Gênero e Educação Infantil e a complementação de filtros selecionando artigos brasileiros, da língua portuguesa, da área de Ciências Humanas e um recorte temporal compreendendo o período de 2000 a 2017. Conclui-se que existem lacunas no processo de formação docente, relacionando-se ao preparo para lidar com a sexualidade. A escassez de pesquisas na área afunila ainda mais quando vinculada à Educação Infantil. O mapeamento de estudos possui elementos contribuintes para a composição de informações e para o possível preenchimento das lacunas concernentes a uma dada área de conhecimento.

PALAVRAS CHAVE: Educação infantil. Formação docente. Gênero.

RESUMEN: El trabajo tiene el objeto de investigar sobre el estudio de género en la enseñanza infantil y la formación docente en este tema. Los datos de la investigación han sido recolectados desde un abordaje bibliográfico. Haciendo uso de la Base de Datos Scielo, utilizando los temas principales: Género y Enseñanza Infantil y la complementación de filtros seleccionando artículos brasileños, de lengua portuguesa, del área de Ciencias Humanas y un recorte temporal abarcando el período de 2000 a 2017. Se concluye que hay huecos en el proceso de formación docente, relacionándose al preparo para lidiar con la sexualidad. La escasez de investigaciones en el área canaliza aún más cuando vinculada a la Enseñanza Infantil. El mapeo de estudios posee elementos contribuyentes par la composición de informaciones y para el posible cubrimiento de los huecos concernientes a un dicho área del conocimiento.

PALABRAS CLAVE: Enseñanza Infantil. Formación docente. Género.

\footnotetext{
${ }^{1}$ Universidade Estadual Paulista (UNESP), Araraquara - SP - Brasil. Programa de Pós-Graduação em Educação Sexual, GEPIFE - grupo de estudos e pesquisas sobre infância, família e escolarização. UNESP/CNPQ. ORCID: <http://orcid.org/0000-0001-9650-0859>.E-mail: arianecrociari@ hotmail.com

${ }^{2}$ Universidade Estadual Paulista (UNESP), Araraquara - SP - Brasil. Programa de Pós-Graduação em Educação Sexual, GEPIFE - grupo de estudos e pesquisas sobre infância, família e escolarização. UNESP/CNPQ. ORCID: <http://orcid.org/0000-0002-4173-9923>.E-mail: marcia.argenti@unesp.br
} 
ABSTRACT: This article aims at research on the study of gender in early childhood education and teacher training in this subject. The research data were obtained from a bibliographical approach. Making use of the Scielo Database, using the main themes: Gender and Early Childhood Education and the complementation of filters selecting Brazilian articles, Portuguese language, Human Sciences and a temporal cut from 2000 to 2017. It is concluded that there are gaps in the teacher training process, relating to the preparation to deal with sexuality. The lack of research in the area is even more important when linked to Early Childhood Education. The mapping of studies has contributory elements for the composition of information and for the possible fulfillment of the gaps concerning a given area of knowledge.

KEYWORDS: Child education. Teacher training. Gender.

\section{Introdução}

Para entendermos melhor o conceito de gênero, devemos voltar nossos olhares a história do movimento feminista contemporâneo. Ele permeou e constituiu todo um movimento marcado por lutas e conquistas. O embate incessante ocasionado pela "inconformidade e desencanto em relação aos tradicionais arranjos sociais e políticos, às grandes teorias universais, ao vazio formalismo acadêmico, à discriminação, à segregação e ao silenciamento" (LOURO, p. 16, 1997), uniu grupos diversificados, expressos por meio de uma heterogeneidade imensa, todos manifestando por um mesmo ideal.

De acordo com Louro (1997), os gêneros são construídos por meio das relações sociais, dentro deste contexto torna-se necessário a consideração do momento histórico e da sociedade em que eles estão inseridos, além de ponderar que no interior de cada sociedade ocorrem também as diferentes concepções de gênero, considerando os diversos grupos que a compõem.

Assim como a concepção de gênero, as compreensões de criança e infância, também são estruturadas historicamente e acabam por refletir a cultura referente ao contexto social no qual a criança encontra-se inserida. Tais conceitos não compreendem estudos recentes, pelo contrário, são alvos de pesquisas desde a Idade Média. Ariès (1973), em seu livro intitulado “ $A$ História Social da Criança e da Família", traça um panorama da Infância a partir do século XII, salientando as diferentes posições que as crianças perpassaram no interior das sociedades.

Agrupando os conceitos, nos deparamos com a importância de trabalhar gênero na Educação Infantil. Este trabalho compete à Educação Sexual aplicada nas escolas pelos docentes. Por meio de pesquisas (CROCIARI e PEREZ, 2018), relatamos a defasagem da formação docente frente a temática imposta.

Ainda de acordo com as autoras: 
A ausência de estudos sobre gênero e educação infantil mostra os desafios de consolidação da ideia de uma educação sexual escolar e de gênero visando o estudo e formação docente baseados nas atribuições sociais que são refletidas na escola e no questionamento de forma que possamos refletir acerca de ideologias culturais, buscando amenizar o silêncio, repressão e preconceito evidenciados já no contexto da Educação Infantil. (CROCIARI; PEREZ, p. $160-161,2018)$.

A Educação Sexual no âmbito escolar, encontra obstáculos que dificultam a sua implementação, consistindo em valores culturais impostos pela sociedade, porém, esse quadro pode refletir mudanças por meio do investimento em formação docente, uma vez que tal preparo influenciará positivamente na constituição escolar como meio concreto para realizar um trabalho eficaz que abarque temas como sexualidade e gênero (RIBEIRO, 2013).

Com base nos conceitos citados e indo ao encontro do objetivo proposto que consiste na investigação sobre o estudo do gênero na educação infantil e a formação docente nesta temática, foi inicialmente realizada uma busca para a realização da averiguação por meio de artigos publicados na Base de Dados Scielo. Tomando-se por base um primeiro levantamento, os quais incluíram os temas "gênero e educação infantil", acrescentando posteriormente os filtros "Brasil; português; Ciências Humanas; 2000 - 2017" nos defrontamos com trinta e sete artigos. Por intermédio de um estudo mais aprofundado dos resumos, fez-se necessário a utilização de uma nova seleção por acreditar que alguns artigos encontravam-se em discordância com as palavras chave sugeridas. O critério destacado para essa nova busca, compreendeu estudos específicos sobre gênero na Educação Infantil incluindo elementos que ressaltam a formação e atuação docente na área, sendo ela qualificada ou defasada. Doze artigos foram então selecionados, correspondendo fielmente ao tema proposto de estudo.

Pensando em uma melhor visualização dos dados, os artigos avistados foram sistematizados na Figura 1, sendo sobrelevados elementos considerados pertinentes para as futuras análises.

\section{Análises}

Por intermédio das pesquisas efetivadas acerca dos artigos antepostos, faz-se necessário a realização de um enquadramento a fim de facilitar a visualização. Com isto, a Figura 1 abaixo apresenta os estudos selecionados e expõe os seguintes elementos: título, objetivo e ano. 
Figura 1 - Elementos considerados pertinentes para análise

\begin{tabular}{|c|c|c|}
\hline Título & Objetivo & Ano \\
\hline $\begin{array}{l}\text { 1. Gênero como possibilidade ou limite da } \\
\text { ação social: um olhar sobre a perspectiva } \\
\text { de crianças pequenas em um contexto de } \\
\text { educação infantil. }\end{array}$ & $\begin{array}{l}\text { - Investigar entre as crianças as formas, significações e as } \\
\text { vias de transmissão de elementos culturais e sociais que } \\
\text { envolvem a dimensão corporal, assim como a emergência } \\
\text { de novos elementos que reforçam, modificam, } \\
\text { multiplicam, transformam, transgridem e transcendem ou } \\
\text { simplesmente ocultam aqueles já estabelecidos. }\end{array}$ & 2013 \\
\hline $\begin{array}{l}\text { 2. Relações sociais de gênero na perspectiva } \\
\text { de crianças pequenas na creche. }\end{array}$ & $\begin{array}{l}\text { - Identificar entre crianças pequenas, em um contexto de } \\
\text { Educação Infantil, formas, significações e vias de } \\
\text { transmissão de elementos culturais e sociais envolvendo a } \\
\text { dimensão corporal. }\end{array}$ & 2013 \\
\hline $\begin{array}{l}\text { 3. Pequena infância, educação e } \\
\text { gênero: subsidios para um estado da arte. }\end{array}$ & - Iniciar a descrição de um estado da arte. & 2006 \\
\hline $\begin{array}{l}\text { 4. Reflexões sobre o comportamento infantil } \\
\text { em um pátio escolar: o que aprendemos } \\
\text { observando as atividades das crianças. }\end{array}$ & $\begin{array}{l}\text { - Investigar a utilização das diferentes áreas do pátio de } \\
\text { uma escola para Educação Infantil e analisar os } \\
\text { comportamentos de interação entre as crianças nesses } \\
\text { locais. }\end{array}$ & 2008 \\
\hline $\begin{array}{l}\text { 5. Masculinidades e docência na educação } \\
\text { infantil. }\end{array}$ & $\begin{array}{l}\text { - Analisar as relações de gênero e a construção da docência } \\
\text { masculina na Educação Infantil, compreendendo como se } \\
\text { dá a escolha e a inserção de homens nesta etapa da } \\
\text { educação. }\end{array}$ & 2017 \\
\hline $\begin{array}{l}\text { 6. Educação Física na Educação Infantil: } \\
\text { educando crianças ou meninos e } \\
\text { meninas? }\end{array}$ & $\begin{array}{l}\text { - Analisar como situações de aula e intervenções docentes } \\
\text { contribuem na construção das relações de gênero, e, em } \\
\text { muitos momentos, classificam e hierarquizam os corpos e } \\
\text { as práticas de meninos e meninas de modo distinto. }\end{array}$ & 2016 \\
\hline $\begin{array}{l}\text { 7. Homens na educação infantil: olhares de } \\
\text { suspeita e tentativas de segregação. }\end{array}$ & $\begin{array}{l}\text { - Analisar a trajetória profissional de sujeitos que compõem } \\
\text { um grupo minoritário na educação: os homens que atuam } \\
\text { como professores de educação infantil. }\end{array}$ & 2014 \\
\hline $\begin{array}{l}\text { 8. Educação infantil: análise da } \\
\text { manifestação social do preconceito na } \\
\text { atividade principal de jogos. }\end{array}$ & $\begin{array}{l}\text { - Levantar indicativos de manifestações preconceituosas em } \\
\text { crianças pré-escolares de } 5 \text { e } 6 \text { anos, na prática de sua } \\
\text { atividade principal. }\end{array}$ & 2011 \\
\hline $\begin{array}{l}\text { 9. Da menina meiga à heroína } \\
\text { superpoderosa: infância, gênero e poder } \\
\text { nas cenas da ficção e da vida. }\end{array}$ & $\begin{array}{l}\text { - Compreender, nas experiências lúdicas das crianças, os } \\
\text { valores que elas constroem ao interagirem com os } \\
\text { personagens e as histórias extraídas dos desenhos } \\
\text { animados contemporâneos, e como esses valores } \\
\text { participam de suas constituições identitárias. }\end{array}$ & 2012 \\
\hline $\begin{array}{l}\text { 10. Meninos na educação infantil: o olhar das } \\
\text { educadoras sobre a diversidade de } \\
\text { gênero. }\end{array}$ & $\begin{array}{l}\text { - Analisar a questão do compartilhamento entre família e } \\
\text { escola, dos cuidados e da educação das crianças de } 0 \text { a } 3 \\
\text { anos. }\end{array}$ & 2010 \\
\hline $\begin{array}{l}\text { 11. Gênero, corpo e sexualidade nos livros } \\
\text { para a infância }\end{array}$ & $\begin{array}{l}\text { - Fazer um balanço dos estudos realizados, buscando } \\
\text { entender essa produção como artefato cultural e como } \\
\text { dispositivo pedagógico de educação da infância, afora } \\
\text { salientar algumas características que expressam como eles } \\
\text { podem ser instrumentos educativos para as crianças. }\end{array}$ & 2014 \\
\hline $\begin{array}{l}\text { 12. Meninas e meninos na Educação } \\
\text { Infantil: uma questão de gênero e poder }\end{array}$ & • Não especificado. & 2009 \\
\hline
\end{tabular}

Fonte: Elaborado pela autora (2019)

Iniciando as análises e indo ao encontro da Figura 1 exposta, nos deparamos com o artigo de Marcia Bus-Simão, intitulado "Gênero como possibilidade ou limite da ação social: um olhar sobre a perspectiva de crianças pequenas em um contexto de educação infantil”". A pesquisa conta com a cooperação de quinze crianças entre dois e três anos.

Bus-Simão (2013a) viabiliza em seus estudos, contribuições acerca das organizações de relações sociais, do procedimento de estruturação de gêneros. Outro conteúdo relevante de 
destaque encontra-se nos estereótipos de gênero, os quais são altamente discutidos com o perpassar do texto.

Como considerações finais do trabalho, Bus-Simão (2013a) salienta que os gêneros não são resultantes de fatores biológicos, mas sim representações de uma construção social de acordo com o momento histórico estabelecido. Como complemento, os estereótipos estão fortemente impregnados na sociedade e as crianças, por sua vez, refutam e/ou reproduzem tais comportamentos.

Prosseguindo com a explanação dos assuntos e trazendo o texto 2 para discussão, continuamos com as contribuições de Marcia Bus-Simão e seu artigo "Relações sociais de gênero na perspectiva de crianças pequenas na creche". Os constituintes da pesquisa abarcavam crianças com idades entre dois e três anos.

Bus-Simão (2013b) concede contribuições clássicas sobre o conceito de gênero interpondo com exemplos práticos vivenciados no âmbito escolar. Outra colaboração importante de se destacar encontra-se nos estereótipos como: força, virilidade e racionalidade competindo ao menino e sensibilidade, afetividade, insegurança representando características próprias das meninas. Bus-Simão (2013b) ressalta que a imposição de tais características reforça segregações e desigualdades.

Como considerações, Bus-Simão (2013b) acentua a existência de outra visão de herói, dando visibilidade a outras masculinidades e atentando-se assim para a capacidade de estar tanto no mundo das meninas como no mundo dos meninos. Com isto acabam por ampliar as possiblidades de amizades e de relações, pois suas interações não se encontram restritas ao seu próprio gênero.

O próximo artigo designado é o texto 3 em questão, com autoria de Ana Lúcia Goulart de Faria e intitulado "Pequena infância, educação e gênero: subsídios para um estado da arte". O estudo aponta pesquisas da área da Educação Infantil, as quais trazem análises pertinentes sobre as relações de poder entre meninas e meninos de zero a seis anos de idade.

Faria (2006) remete brevemente a atenção para o ingresso em massa das mulheres no mercado de trabalho, culminando na predominância de profissionais do sexo feminino em instituições de Educação Infantil. E finaliza destacando que crianças pequenas, dispostas em âmbitos coletivos de educação, trazem consigo uma bagagem farta de histórias e culturas já internalizadas, advindas de experiências familiares.

Transpondo para o texto 4, composto por estudos de Odara de Sá Fernandes e Gleice Azambuja Elali, nos deparamos com o artigo "Reflexões sobre o comportamento infantil em 
um pátio escolar: o que aprendemos observando as atividades das crianças". Os partícipes são compostos por dezesseis crianças com idades entre três e sete anos.

Fernandes e Elali (2008) destacam a escola como um ambiente primordial para o desenvolvimento, trazendo a importância e significância para o pátio escolar, o qual se encontra caracterizado como um meio para a interação social. Este por sua vez, necessita de equilíbrio, pois um número demasiadamente grande de alunos pode ocasionar hostilidade e um número ínfimo pode gerar pouca socialização. Os estudos também explicitam que o recreio sendo composto por crianças discernidas pela faixa etária, provoca um impedimento da troca de experiências e aprendizado em grupo.

Mediante os artigos selecionados anteriormente, ocorreu a publicação da pesquisa das autoras Angelita Alice Jaeger e Karine Jacques, "Masculinidades e docência na educação infantil”. A amostra da pesquisa incorpora três professores da Educação Infantil.

Jaeger e Jacques (2017) denotam os percalços vivenciados pelos professores de instituições infantis, assim como suas superações para o possível aceite da comunidade escolar. Quebrando os paradigmas impostos, tais professores contestam o padronizado para o seu sexo e enunciam diferentes formas de masculinidade, incluindo sentimentos como afeto, cuidado e delicadeza.

Continuando a explanação, transcorremos para o texto 6. As autoras Marina Mariano e Helena Altmann publicaram o artigo "Educação Física na Educação Infantil: educando crianças ou meninos e meninas?".

Mariano e Altmann (2016) através de observações ocorridas no interior da escola destacaram as diferenças de duas turmas de escolas distintas: uma de um professor e outra de uma professora. O professor propunha atividades mistas, sem distinção de gênero e a inexistência de discursos discriminatórios. A professora, por sua vez, fazia uso de elocuções estereotipadas que acabavam por reforçar as desigualdades de gênero. Ambas as atitudes refletiam negativamente e positivamente nas crianças, de acordo com os resultados da pesquisa, os quais ressaltavam que a atuação docente influenciava no comportamento, nas ações e na organização das crianças.

Caminhando para o texto 7, "Homens e Educação Infantil: olhares sob suspeita e tentativas de segregação" escrito por Mariana Kubilius Monteiro e Helena Altmann. As autoras contaram com a colaboração de sete professores.

Considerando dados relatados no artigo, a Educação Infantil envolve um ambiente constituinte, em sua maioria, pela presença de mulheres, os homens por sua vez, possuem um espaço restrito. A comprovação e possível explicação dão-se através da caracterização do 
trabalho das mulheres como esfera reprodutiva e o trabalho dos homens como esfera produtiva, uma vez que os papéis sociais são considerados sexuados limitando o gênero ao sexo biológico.

Por intermédio de entrevistas semiestruturadas, Monteiro e Altmann (2014) puderam assimilar as dificuldades de aceitação e os percalços pelos quais passam os profissionais docentes no âmbito de uma instituição de Educação Infantil. Olhares de segregação e suspeita são constantemente lançados para tais profissionais, tornando-se emergente então, a possibilidade de outras noções de masculinidade, que incluam o cuidar e o educar, a fim de eliminar tais discriminações.

Seguindo a Figura 1, nos deparamos com o texto 8, intitulado "Educação Infantil: análise da manifestação social do preconceito na atividade principal de jogos" por Gustavo Martins Piccolo.

A partir dos resultados explanados por Piccolo (2011), constatou-se que por meio de atividades ocasionadas no âmbito escolar, as crianças refletiam manifestações preconceituosas. Assume-se então, a importância da intervenção docente, para que ocorra o direcionamento das brincadeiras a fim de extinguir desigualdades, uma vez que as atitudes das crianças, sendo elas discriminatórias ou não, são reflexos da sociedade e da cultura em que ela se encontra inserida.

De acordo com as considerações finais, encontra-se em um patamar relevante de consideração a necessidade de intervenção, a importância de atividades lúdicas com auxílio de um mediador a fim de identificar ferramentas com o propósito de contestar as contradições e estereótipos e a existência de práticas pedagógicas voltadas para a transformação da sociedade.

Prosseguindo com o mapeamento, Raquel Gonçalves Salgado publicou seu artigo "Da menina meiga à heroína superpoderosa: infância, gênero e poder nas cenas da ficção e da vida". O objeto de estudo englobou vinte e uma crianças, de cinco a seis anos de idade.

Salgado (2012) constata que a mídia televisiva se apresenta como uma adulteração dos limites entre o mundo adulto e o infantil, a qual acaba por contribuir para a precocidade e por consequência, para o desaparecimento da infância. A cultura do consumo, exposta pela televisão e constantemente incorporada e internalizada pelas crianças, consagram-na como herói e protagonista, libertando-as das práticas adultas que a denominavam como um ser frágil e indefeso.

Continuando as explanações, nos deparamos com o texto 10, "Meninos na educação infantil: o olhar das educadoras sobre a diversidade de gênero", de Isabel de Oliveira e Silva e Iza Rodrigues da Luz. Tal estudo apresentou como objeto de estudo, professoras e crianças de zero a três anos de idade. 
Silva e Luz (2010) apresentam contribuições pertinentes acerca das relações de gênero observadas no âmbito escolar e no reflexo das professoras da instituição. Elas enfatizam que durante as observações, constataram que as educadoras eram orientadas por concepções de masculino e feminino que remetiam a papéis estereotipados de homem e de mulher.

Encaminhando para o final da caracterização dos estudos, destaca-se o texto 11, "Gênero, corpo e sexualidade nos livros para a infância", publicado pela Constantina Xavier Filha. A pesquisa identificou e coletou um total de trezentos e sessenta e um livros, os quais apresentavam temáticas de sexualidade e gênero.

De acordo com a linha cronológica exposta por Xavier Filha (2014), os livros infantis de 1930 a 1970 destacavam-se pela linguagem arbitrária e padronizada a respeito da sexualidade da criança. A partir da década de 1970, observou-se uma maior conformidade do texto e das ilustrações com o leitor. E nas publicações recentes, apresentam-se por intermédio de uma linguagem lúdica, trazendo conteúdos que remetam a reflexões e discussões de temas infantis.

Terminando a investigação proposta, nos deparamos com o artigo 12 de Claudia Vianna e Daniela Finco, "Meninas e meninos na Educação Infantil: uma questão de gênero e poder". Vianna e Finco (2009) destacam no início do texto que as preferências e as características de meninos e meninas representam construções sociais e históricas, não compreendendo fatores biológicos. $\mathrm{O}$ artigo apresenta como considerações finais a importância da atuação docente, as quais reforçam ou extinguem as desigualdades impostas pela sociedade. As professoras participantes da pesquisa em questão acabavam por reforçar estereótipos de gênero entre seus alunos.

\section{Resultados}

Um tema considerado de extrema relevância encontra-se no patamar da formação e atuação docente. Por ser apresentado e enfatizado nos artigos selecionados, faz-se necessário o levantamento de algumas questões acerca da formação do profissional na área da sexualidade, do papel do professor no âmbito escolar de uma instituição infantil atrelado as suas contribuições para a desconstrução ou afirmação dos estereótipos de gênero.

Dentre os 12 artigos selecionados, poucos fazem menção à importância da formação e da atuação docente. Porém, quase que em sua totalidade, apresentam exemplos enriquecedores das transformações positivas e negativas que este profissional acarreta na formação acadêmica 
de seus alunos e principalmente na contribuição que estes trazem para a construção das relações de gênero.

Segundo Mariano e Altmann (2016), artigo 6 exposto na Figura 1, a diferença entre as atuações docentes pode ser notada com facilidade em sua pesquisa, por possuir como sujeitos um professor e uma professora. A atuação de ambos os profissionais demonstrava atitudes e reflexos opostos. $\mathrm{Na}$ escola em que o atuante era o professor, o qual apresentava atividades mistas, não separando as crianças por gêneros, estas se mostravam livres, bem resolvidas e eram capazes de formar diversos grupos ao decorrer das atividades sem demarcar as diferenças. Contrariamente, a escola que possuía a contribuição da professora, tal qual trazia em seus discursos falas discriminatórias e a separação das crianças em gêneros era recorrente, os alunos incorporaram as atitudes demonstradas cotidianamente pelo profissional docente e refletiam instantaneamente essa divisão de mundo em suas organizações sociais. O estudo demonstra que intervenções menos diretivas, isto é, intervenções em que o professor não demonstrava e enfatizava suas visões de mundo, suas opiniões próprias, acabavam por não influenciar negativamente as crianças, produzindo relações de gênero menos hierarquizadas e, por consequência, menos desiguais, uma vez que "as desigualdades entre homens e mulheres são construídas pela sociedade e não determinadas pela diferença biológica entre os sexos. Elas são uma construção social, não determinada pelo sexo." (FARIA; NOBRE, 2003, p. 2).

Faz-se necessário destaque para o trabalho da Educação Sexual no combate à discriminação, atos e atitudes preconceituosas, além de desconstruir hierarquias de gênero refletidas pela sociedade e possivelmente reforçadas no âmbito escolar. Tal educação deve fornecer elementos essenciais para a criação de um espaço onde as crianças consigam problematizar e contextualizar os conceitos por meio de práticas eficazes. (LEÃO, 2012).

Silva e Luz (2010), artigo 10 da Figura 1, demonstram que as educadoras participantes da pesquisa traziam consigo concepções prontas, estereotipadas e culturais do que era ser menino e menina. Tais comportamentos eram reproduzidos e representados nas práticas das crianças, refletindo formas estereotipadas.

De acordo com o Referencial Curricular Nacional para a Educação Infantil:

[...] mesmo quando o ambiente é flexível quanto às possibilidades de exploração dos papéis sociais, os estereótipos podem surgir entre as próprias crianças, fruto do meio em que vivem, ou reflexo da fase em que a divisão entre meninos e meninas se torna uma forma de se apropriar da identidade sexual. (BRASIL, 1998, p. 42). 
O enfoque não consiste em naturalizar os comportamentos de meninos e meninas e nem em desconsiderar que tais condutas sejam frutos de construções históricas, sociais e culturais, mas sim apontar como eficiente o papel do professor no tocante a desconstrução ou reprodução de tais costumes.

Para garantir uma prática docente eficaz, torna-se necessário o investimento em "uma base bem solidificada de maneira que o profissional tenha acesso ao conhecimento teórico e didático que necessita para uma prática pedagógica eficaz e diferenciada" (LEÃO; RIBEIRO, p. 613, 2013). Ainda de acordo com os autores citados, as disciplinas que abarcam o tema educação sexual, encontram-se escassas nas graduações que oferecem cursos de licenciatura, exatamente os cursos que precisam se responsabilizar perante a formação de seus profissionais no tocante ao trabalho do tema em questão.

E por fim, Vianna e Finco (2009), apresentam distintas formas de contribuir para as desigualdades de gênero. O estudo demonstra que, de acordo com o contexto histórico inserido, instituições acabam por orientar e reforçar habilidades específicas e distintas para meninos e meninas. As professoras participantes da pesquisa controlavam a agressividade nas meninas e a sensibilidade nos meninos, excluindo ambos de situações das quais poderiam ocorrer tais demonstrações.

Por meio dos relatos expostos, devemos destacar que:

[...] compete à escola criar condições de ensino e aprendizagem, e de formação e reflexão para questões de sexualidade, gênero e educação sexual, que paulatinamente contribuiriam para esclarecer, diminuir e, até erradicar estes mitos, tabus e preconceitos de natureza sexual (LEÃO; RIBEIRO, p. 615, 2013)

Para tal feito, faz-se necessário a formação do profissional educacional na área a fim de identificar em suas práticas, elementos eficazes para eliminar, desde a tenra idade, relações discriminatórias, contribuindo para o amparo e desenvolvimento pleno de seus alunos.

\section{Conclusão}

Podemos concluir que o processo de formação docente se encontra defasado no tocante às questões relacionadas a sexualidade, o que ocasiona uma série de lacunas prejudiciais ao trabalho pedagógico docente. Há especificidades de valor elogiável que precisam ser consideradas no processo de formação inicial dos professores, uma vez que os quais precisam estar capacitados para acarretar em conhecimentos pertinentes. 
A atuação docente, como observado, relata exemplos claros da total influência das práticas pedagógicas para o processo de conhecimento dos alunos. Portanto, o professor deve considerar que está diante de uma sala heterogênea e que cada criança carrega consigo uma imensa bagagem cultural advinda de conhecimentos espontâneos, sendo fruto de experiências vividas no âmbito familiar. Atentar aos elementos acima resulta para o professor em ferramentas valorosas para discorrer cotidianamente sobre atividades, brincadeiras e conversas livres de preconceitos e desigualdades.

E por fim, a intervenção docente acaba por acarretar em atitudes internalizadas pelas crianças, cabendo ao professor fornecer mecanismos que busquem o progresso igual de seus alunos, contribuindo para a desconstrução da desigualdade de gêneros.

\section{REFERÊNCIAS}

ARIÈS, P. História social da criança e da família. 2. ed., Rio de Janeiro: Guanabara. 1973.

BRASIL. Ministério da Educação e do Desporto. Secretaria de Educação Fundamental. Referencial curricular nacional para a educação infantil. Ministério da Educação e do Desporto, Secretaria de Educação Fundamental. — Brasília: MEC/SEF. 1998.

BUSS-SIMAO, M. Gênero como possibilidade ou limite da ação social: um olhar sobre a perspectiva de crianças pequenas em um contexto de educação infantil. Rev. Bras. Educ.[online]. v. 18, n. 55, p. 939-960, 2013. ISSN 1413-2478.

BUSS-SIMAO, M. Relações sociais de gênero na perspectiva de crianças pequenas na creche. Cad. Pesqui. [online]. v. 43, n. 148, p. 176-197, 2013. ISSN 0100-1574.

CROCIARI, A.; PEREZ, M. C. A. Docência, Gênero e Educação Infantil: sistematizando os poucos estudos encontrados. Anais do III Congresso de Educação PET Pedagogia: XII Amostra de Pesquisas em Educação. Marcia Cristina Argenti Perez (Org.). Araraquara, 2018 (Brasil). - Documento eletrônico. - Araraquara: FCLar-UNESP, p. 160, 2018.

FARIA, A. L. G. de. Pequena infância, educação e gênero: subsídios para um estado da arte. Cad. Pagu [online]. n. 26, p. 279-287, 2006. ISSN 1809-4449.

FARIA, N.; NOBRE, M. O que é ser mulher? O que é ser homem? Subsídios para uma discussão das relações de gênero. In: COORDENADORIA especial da mulher (org.). Gênero e educação: caderno para professores. São Paulo, Secretaria Municipal de Educação, p. 2942, 2003.

FERNANDES, O. de S.; ELALI, G. A. Reflexões sobre o comportamento infantil em um pátio escolar: o que aprendemos observando as atividades das crianças. Paidéia (Ribeirão Preto) [online]. v. 18, n. 39, p. 41-52, 2008. ISSN 0103-863X. 
JAEGER, A. A.; JACQUES, K. Masculinidades e docência na educação infantil. Rev. Estud. Fem.[online]. v. 25, n. 2, p. 545-570, 2017. ISSN 0104-026X.

LEÃO, A. M. C. A percepção dos (as) professores (as) e coordenadores(as) dos cursos de Pedagogia da Unesp quanto à inserção da sexualidade e da educação sexual no currículo: analisando os entraves e as possibilidades para sua abrangência. Relatório de PósDoutorado (Sexologia e Educação Sexual) - Faculdade de Ciências e Letras, Universidade Estadual Paulista, Araraquara. 259 p., 2012.

LEÃO, A. M. C.; RIBEIRO, P. R. M. Curso de formação inicial em sexualidade: relato de uma proposta interventiva. Revista Ibero-Americana de Estudos em Educação, v. 8, n. 3, 2013.

LOURO, G. L. Gênero, sexualidade e educação: Uma perspectiva pós-estruturalista. Petrópolis, RJ Vozes. 1997.

MARIANO, M.; ALTMANN, H. Educação Física na Educação Infantil: educando crianças ou meninos e meninas? Cad. Pagu [online]. n. 46, p. 411-438, 2016. ISSN 0104-8333.

MONTEIRO, M. K.; ALTMANN, H. Homens na educação infantil: olhares de suspeita e tentativas de segregação. Cad. Pesqui.[online]. v. 44, n. 153, p. 720-741, 2014. ISSN 01001574.

PICCOLO, G. M. Educação infantil: análise da manifestação social do preconceito na atividade principal de jogos. Educ. Soc.[online]. v. 32, n. 114, p. 205-221, 2011. ISSN 01017330 .

RIBEIRO, P. R. M. A educação sexual na formação de professores: sexualidade, gênero e diversidade enquanto elementos para uma cidadania ativa. In: RABELO, A. O.; PEREIRA, G. R.; REIS, M. A. S. (Org.). Formação docente em gênero e sexualidade. Petrópolis: DP et al.p. 7-15, 2013.

SALGADO, R. G. Da menina meiga à heroína superpoderosa: infância, gênero e poder nas cenas da ficção e da vida. Cad. CEDES [online]. v. 32, n. 86, p. 117-136, 2012. ISSN 01013262 .

SILVA, I. de O.; LUZ, I. R. da. Meninos na educação infantil: o olhar das educadoras sobre a diversidade de gênero. Cad. Pagu [online]. n. 34, p. 17-39, 2010. ISSN 1809-4449.

XAVIER FILHA, C. Gênero, corpo e sexualidade nos livros para a infância. Educ. rev.[online]. n. esp. 1, p. 153-169, 2014. ISSN 0104-4060.

VIANNA, C.; FINCO, D. Meninas e meninos na Educação Infantil: uma questão de gênero e poder (2009). Cad. Pagu [online]. n. 33, p. 265-283, 2009. ISSN 1809-4449. 


\section{Como referenciar este artigo}

CROCIARI, Ariane; PEREZ, Marcia Cristina Argenti. O que estamos estudando sobre gênero na educação infantil: as lacunas na formação docente. Revista Ibero-Americana de Estudos em Educação, Araraquara, v. 14, n. esp. 2, p. 1556-1568, jul., 2019. E-ISSN: 1982-5587. 10.21723/riaee.v14iesp.2.12615

Submetido em: 30/09/2018

Revisões requeridas: 20/02/2019

Aprovado em: 30/04/2019

Publicado em: 26/06/2019 